\title{
Do schools promote violence in Sri Lanka?
}

(Index words: Corporal punishment, teachers' views)

\section{Introduction}

There is growing interest on the health and social issues related to violence. A recent publication by the World Health Organization (WHO) has created wide interest on the subject in medical publications [1-3].

Sri Lanka is considered to be a violent country with a history of a prolonged armed conflict, insurrections in 1971 and 1989, ethnic violence in 1983, and currently has high suicide and homicide rates. Several publications have emphasised suicide and related problems in Sri Lanka [4,5]. However, the health and social problems related to homicide have received scant attention. This is surprising because in 1996 suicide and self-inflicted injury caused 5519 deaths in contrast to 11196 caused by homicides and injury deliberately inflicted by others [6]. The leading cause of death among the 15 to 49 year age group in the country during the same year was due to injury so inflicted (excluding deaths due to war) [7]. Violence has other social costs such as its burden to the country's legal and judicial system. Its socio-economic costs and psychological costs have never been estimated in our country.

The WHO report [1] describes an ecological model to explain the multi-dimensional nature of violence and its roots in a society. This model is described as a public health approach that can be used to identify the determinants of violence and the appropriate preventive measures. Four inter-related "levels" (or factors) of the model are individual, relationship, community and society. The societal factor is to "create an acceptable climate for violence.... and include cultural norms that support violence as an acceptable way to resolve conflicts".

Qualitative data from a recent study on those who have committed homicide or had ideations of violence towards others and their family and friends, indicate the presence of a social norm of using physical and verbal aggression as a means to resolve conflicts [8]. Some participants describe a series of life events from childhood, which eventually leads them to perform the role of a violent person prone to commit such acts. More worrying was the acceptance by the community who participated in the focus groups that violence is a justified means to an end, and considered it as a norm. Other researchers have described a "conflict culture" existing in Sri Lanka, which promotes aggressive behaviour and violence between individuals [9].

How could our country develop such behavioural patterns leading to violence and these social norms? The often blamed culprit is the conflict in the northern and eastern Provinces, which has affected all forms of society for the past 20 years. We do not believe this to be the sole explanation, for a number of reasons. Firstly, the rate of violence is high in areas distant from the regions with conflict [10]. Secondly, high rates of homicide have been a feature of the country for many decades [10]. Thirdly, the detailed ethnographic studies could not identify racial prejudices or race related violence as a critical factor [8]. These findings prompted us to look at more widespread social institutions in the country and to investigate their potential in promoting these norms and cultural values (i.e. the social level of the ecological model). This study reports on data from schools. The objective was to study whether adolescent schoolchildren were subject to physical punishment by teachers, and to describe the perceptions of students and teachers of such punishment.

\section{Methods}

The cross-sectional study was carried out on students attending GCE "O" Level and "A" Level classes. A convenient sample of tuition classes was selected from main urban centres in seven Provinces. Schools were avoided for two reasons. Firstly, we were not optimistic about the cooperation from school authorities for such a study, and secondly, it was unlikely that students would have felt comfortable to give honest answers when questioned within the school premises.

Trained research assistants visited the popular tuition classes. The tutors were told about the study and their cooperation obtained to distribute a questionnaire at the end of a class. One thousand questionnaires were distributed (100 each to students attending classes in Anuradhapura, Gampaha, Polonnaruwa, Kurunegala, Badulla, Ratnapura, Kandy and Galle, and 200 in Colombo).

The questionnaire was anonymous and included questions on study methods, physical environment for studying, distance from school, and several questions on the learning environment. The last included questions on physical punishment by teachers in school. The data are presented here on this aspect.

Subsequently, a purposive sample of 15 teachers and 22 students (from a leading school in Colombo) underwent open-ended interviews on physical punishment by one of the authors (D de S). Their narratives were transcribed soon after the interview and coded for recurring themes. Open-ended questions were asked to encourage the participants to describe their emotions, feelings and experiences related to physical punishment.

\section{Results}

The study was conducted in November and December 2000. There were 976 students from 197 
schools (115 mixed, 43 girls' schools and 39 boys' schools) who answered the questionnaire, and $38.6 \%$ of the sample were boys. They were from nine Districts in seven Provinces.

Sixty-two students $(6.4 \%)$ experienced physical punishment by teachers during the preceding 4 weeks and $156(16 \%)$ during the year 2000. Those who witnessed physical punishment of other students during the preceding 4 weeks was $552(56.6 \%) ; 688(70.5 \%)$ recalled witnessing such an event during the year 2000 .

We could identify 45 schools with $\geq 5$ students (mean $=16$ students per school). In 17 of these schools $(37.8 \%)$, more than 1 in 5 students (i.e. $20 \%$ ) had experienced physical punishment during 2000.

The qualitative study showed that students who were physically punished felt humiliated or angry because of the punishment. Students who witnessed physical punishment felt sorry for their friends, but justified the need to use it as a correctional method. Six students were from leading private or "international schools," which did not use such methods, and the children from these schools categorically condemned all forms of physical punishment.

Teachers fell into three groups: those who favoured and argued in support of physical punishment believed that children are unruly, naughty and have to be corrected with force. Those who opposed it considered children to be innocent individuals who needed love, tenderness and sympathetic guidance. The third group consisted of a few who had used physical punishment in the past, and found that they had made an error in judgement and regretted having used it. They stated that they automatically started using physical punishment early in their career, as it was a norm in the respective schools, but with experience they realised the negative consequences of such punishment.

\section{Discussion}

Experiencing or witnessing physical punishment appears to be a common feature in schools. More than one-third (37.8\%) of the schools used physical punishment regularly and an appreciable number of children $(6.4 \%)$ were punished during the preceding 4 weeks. The rate may be higher in the school population if one assumes that it is the keener student who attends tuition classes. Though the sampling was not random, the large number of students from several centres around the country indicates that these findings are valid.

Physical punishment affects self-esteem of growing children and they may develop into adults who use physical violence to solve problems. The impact of physical punishment on children has been extensively studied and many reports condemn its use because of its potential harm to children, specially the long term implications on psychological development $[11,12]$. Even the short term physical punishment by teachers results in severe psychological distress. One of us has come across several instances of children refusing to go to school and undergoing psychological distress due to physical punishment by teachers (unpublished). In a study of school going adolescents, the key sources of emotional distress in those with suicidal ideation were relationships with family, corporal punishment and strictness of parents [13].

Other studies also show that violence and abuse as a means of "control" is common in families, which form the major social institutions in the country [14]. Recent data have confirmed these observations in smaller subgroups. Several studies have shown a high frequency of repeated physical abuse of women by their partners [15, 16]. A clinic based study of patients with psychiatric illness revealed $30 \%$ of them having experienced physical violence inflicted mainly by family members [17]. In a preliminary survey of mothers attending 10 clinics in the Gampaha District, "hitting a small child in order to discipline" was found to be the norm (Shirmila Mendis, Saroj Jayasinghe, personal communication). In another study on adolescents who attempted suicide, parental abuse was found to be a factor in $48.5 \%$ of them [18].

The qualitative data from the study appear to indicate that children who attend schools which practice corporal punishment accept it as the norm, whereas it is not so in other schools. The relatively high rate of physical punishment despite an administrative circular against its use shows a high degree of its acceptance by teachers [19]. Violence against children is a clear violation of human rights as enshrined in the UN Convention on Child Rights, to which Sri Lanka is a signatory. Newly introduced programs to enhance self-esteem of children and peace education in the schools would sound hollow to many children who repeatedly witness or experience beatings at the hands of their teachers. Urgent remedial measures need to be taken to reverse this trend as one way of reducing violence in our society. It is the duty of health professionals to draw attention of the society to this problem in the country $[1,2,20]$.

\section{Acknowledgements}

We thank Dr. Inthikab Allam for assistance in data analysis, and PHAG Kumara and KVC Keppetipola for data collection.

\section{References}

1. Krug EG, Dahlberg LL, Mercy JA, Zwi AB, Lozano R, eds. World report on violence and health. Geneva: World Health Organisation, 2002.

2. Krug EG, Mercy JA, Dahlberg LL, Zwi AB. The world report on violence and health. Lancet 2002; 360: 1083

3. Heath I. Treating violence as a public health problem. British Medical Journal 2002; 325: 726-7. 
4. De Silva D, Jayasinghe KSA. Suicide in Sri Lanka. In: Vijayakumar L, ed. Suicide Prevention. India: Orient Longman Private limited, 2003: 178-90.

5. World Health Organisation (WHO). Figures and Facts about Suicide. Geneva: WHO, 1999.

6. Department of census and statistics. Statistical abstract 2000: 74. Sri Lanka: Ministry of Financing and Planning.

7. Annual Health Bulletin. Sri Lanka: Department of Health Services 2000; 96: 12.

8. De Silva D, Abeysinghe R, Kasthuriarachchi N. Preventing suicide, homicide and non-fatal harm in Sri Lanka. Research report. World Health Organisation, 2002.

9. Department of Police: Division of Statistics, Sri Lanka 1992-2001.

10. Bolz W. Psychological analysis of the Sri Lankan conflict culture with special reference to the high suicide rate. Crisis 2002; 23: 167-70.

11. Friedman SB, Schonberg SK, eds. Conference proceedings on the short and long term consequences of corporal punishment. Paediatrics 1996; 98: (Suppl.) 803-57.

12. Waterstone T. Giving guidance on child discipline. British Medical Journal 2000; 320: 261-2.

13. Wickremasinghe SC, Rajapakse I. Prevalnce and some correlates of emotional disorders among 15-19 year old school children in a $\mathrm{MOH}$ area. Abstracts of the fifth annual scientific sessions of the College of Community Physicians of Sri Lanka, 2000.

14. Samarasinghe G. The incidence of domestic violence in four locations in Sri Lanka and the attitude of women towards violence. Research report. Colombo: Women in Need, 1991.

15. Hussein A. Sometimes there is no blood: Domestic violence and rape in rural Sri Lanka. Research report. Sri Lanka: International Centre for Ethnic Studies, 2000.

16. De Silva D, Dassanayake P. Partner violence among women seeking psychiatric outpatient care: a quantitative and qualitative inquiry. 116th anniversary academic sessions, Sri Lanka Medical Association, 2003: 46.

17. De Silva D, Kulatunge M, Hettiarachchi D, Peiris A, Pathirana W. Abuse and Deliberate self harm in psychiatric patients: a clinic based study. Annual academic sessions, Faculty of Medical Sciences, Sri Jayawardenapura. 2001: 2.

18. Abeysinghe DRR. Psychiatric aspects of pesticide poisoning. In: Smit L A M, ed. Pesticides: Health Impacts and Alternatives. Colombo, Sri Lanka. International Water Management Institute, 2002: 12-15.

19. Ministry of Education. Maintaining discipline in schools. Circular No: 2001/11. 2001.03.30 Sri Lanka: Isurupaya, Sri Jayawardenapura.

20. Soothill K. A new report on violence-welcome and a warning. The British Journal of Psychiatry 2003; 182: 3-4.

Damani de Silva, Senior Lecturer, Department of Psychological Medicine, and Saroj Jayasinghe, Associate Professor, Department of Clinical Medicine, Faculty of Medicine, Kynsey Road, Colombo 8, Sri Lanka.

Correspondence: SJ, e-mail: sarojoffice@yahoo.com (Competing interests: none declared). Received 7 June and accepted 24 June 2003. 